\title{
A Comparative Study of Mast Cells Count in Different Histological Grades of Oral Squamous Cell Carcinoma by Using Toluidine Blue Stain
}

\author{
Keerthi V. Narayan ${ }^{1}$, Grace Sonia ${ }^{2}$, Parikshya Shrestha ${ }^{3}$, Girish Hemadala ${ }^{2}$ \\ 1. Department of Oral and Maxillofacial Pathology, Dr. M.G.R. Educational and Research Institute, Chennai, IND 2. \\ Department of Oral and Maxillofacial Pathology, Rajarajeswari Dental College and Hospital, Bangalore, IND 3. \\ Department of Oral and Maxillofacial Pathology, KIST Medical College and Teaching Hospital, Lalitpur, NPL
}

Corresponding author: Grace Sonia, gracesonia05@yahoo.com

\section{Abstract}

Background

Oral squamous cell carcinoma (OSCC) is the sixth most common cancer worldwide accounting for $90 \%$ of all malignant oral lesions with high mortality and a five-year survival rate of about $50 \%$. Various studies have shown mast cells regulate carcinogenesis by immunosuppression, angiogenesis enhancement, and promotion of tumor cell mitosis.

Aim

Hence, the present study was aimed to compare mast cell counts in normal oral mucosa with histological grades of oral squamous cell carcinoma by using toluidine blue stain.

Methodology

Sixty formalin-fixed, paraffin-embedded tissue samples included 15 well-differentiated, 15 moderately differentiated, and 15 poorly differentiated OSCC, as well as 15 cases of the normal oral mucosa (control), were sectioned and stained with $1 \%$ toluidine blue.

Results

We observed that the mean mast cell (MMC) count was comparatively more in normal mucosa than in various grades of OSCC. It was higher in low-grade OSCC. However, the differences between grades were not statistically significant.

\section{Conclusion}

Review began 09/13/2020 Review ended 09/15/2020 Published 09/24/2020

\section{(c) Copyright 2020}

Narayan et al. This is an open access article distributed under the terms of the Creative Commons Attribution License CC-BY 4.0., which permits unrestricted use, distribution, and reproduction in any medium, provided the original author and source are credited.
In the present study, according to the results obtained, the MMC count was significantly decreased in OSCC in comparison with normal oral mucosa. Therefore, it can be assumed that mast cells could serve as an indicator of tumor progression.

Categories: Pathology, General Surgery, Oncology

Keywords: research in angiogenesis, mast cell, squamous cell carcinoma, toluidine blue, oncopathology, tumor progression

\section{Introduction}

Oral squamous cell carcinoma (OSCC) represents $90 \%$ of head and neck malignant tumors. OSCC can be broadly described as a malignant neoplasm of stratified squamous epithelial origin with the highest recurrent invasion. Alcohol consumption and tobacco smoking still remain the primary etiological agents of OSCC, along with predisposing factors such as ultraviolet radiation or human papillomavirus infection. Histologically, SCC of the head and neck region is categorized as a well-differentiated, moderately differentiated, or poorly differentiated type based on the nature of the cell differentiation [1].

Mast cells (MCs) are large connective tissue cells with numerous basophilic cytoplasmic granules rich in histamine and heparin, which originated from hematopoietic bone marrow precursor cells and are frequently found scattered along the capillaries. In 1877, Paul Ehrlich identified the MC and termed it as mastzellan, which denotes "a well-fed cell” with intracellular granules contained phagocytosed material or nutrients that could be food for neighbor cells [2]. Histologically, MCs are heterogeneous in shape, varying from round, oval, or spindle-shaped, of about 12 microns (diameter) with 50 - 100 packed granules. It is often 
difficult to distinguish fibroblasts from MCs in routine hematoxylin and eosin (H\&E) stain owing to its similar staining characteristics. Hence, a selective metachromatic stain of $1 \%$ toluidine blue was used first in 1856 by British chemist William Henry Perkin who illustrated purplish-red MCs with the nuclei appearing sky blue in color [3].

Numerous studies have shown the association of these normal cells with resistance and susceptibility in the tumor advancement process. Because of these unique properties, these cells are ideally poised to aid as 'gatekeepers' of the normal and tumor microvasculature in the oral cavity [4-5]. Angiogenesis is the growth of new blood vessels from the preexisting ones that necessitate the continued growth and survival of neoplasms. In many human malignancies, angiogenesis has been regulated by a balance between stimulators and inhibitors of angiogenic factors. It has been hypothesized that the angiogenic phenotype may result from the production of various growth factors, such as fibroblast growth factor-2 (FGF-2) and vascular endothelial growth factor (VEGF) by the tumor cells and/or the down-regulation of negative modulators, like thrombospondin-1 (TSP-1) in tissues with dormant vasculature [6-7] However, very few studies were performed over the years to understand the nature of the $\mathrm{MC}$ in the tumor angiogenesis and progression. Hence, the present study was aimed to compare mast cell counts (MMCs) in normal oral mucosa with various histological grades of oral squamous cell carcinoma by using toluidine blue stain.

\section{Materials And Methods}

The study was conducted on 60 formalin-fixed, paraffin-embedded tissue samples that were retrieved from the archives of the Department of Oral and Maxillofacial Pathology, RajaRajeswari Dental College and Hospital, Bangalore. The study included 15 cases of histologically confirmed, well-differentiated OSCC, 15 cases of moderately differentiated OSCC, 15 cases of poorly differentiated OSCC, and 15 cases of the normal oral mucosa. The paraffin infiltrated tissues embedded in wax blocks were sectioned to a thickness of $5 \mu \mathrm{m}$ using a soft tissue semi-automatic microtome. One set of the section was subjected to routine H\&E staining to re-confirm the histopathological diagnosis. Another set of the section was stained by acidified $1 \%$ toluidine blue as per protocol for MCs metachromatic staining technique. All stained sections were examined under a binocular light microscope. Five areas were randomly selected at low power $(4 \mathrm{x})$ to identify the area of hot spots and the MCC was evaluated under high power (40x) for each specimen. The areas under one high-power field (HPF) were taken as one microscopic field (photomicrographs 1, 2, 3, 4).

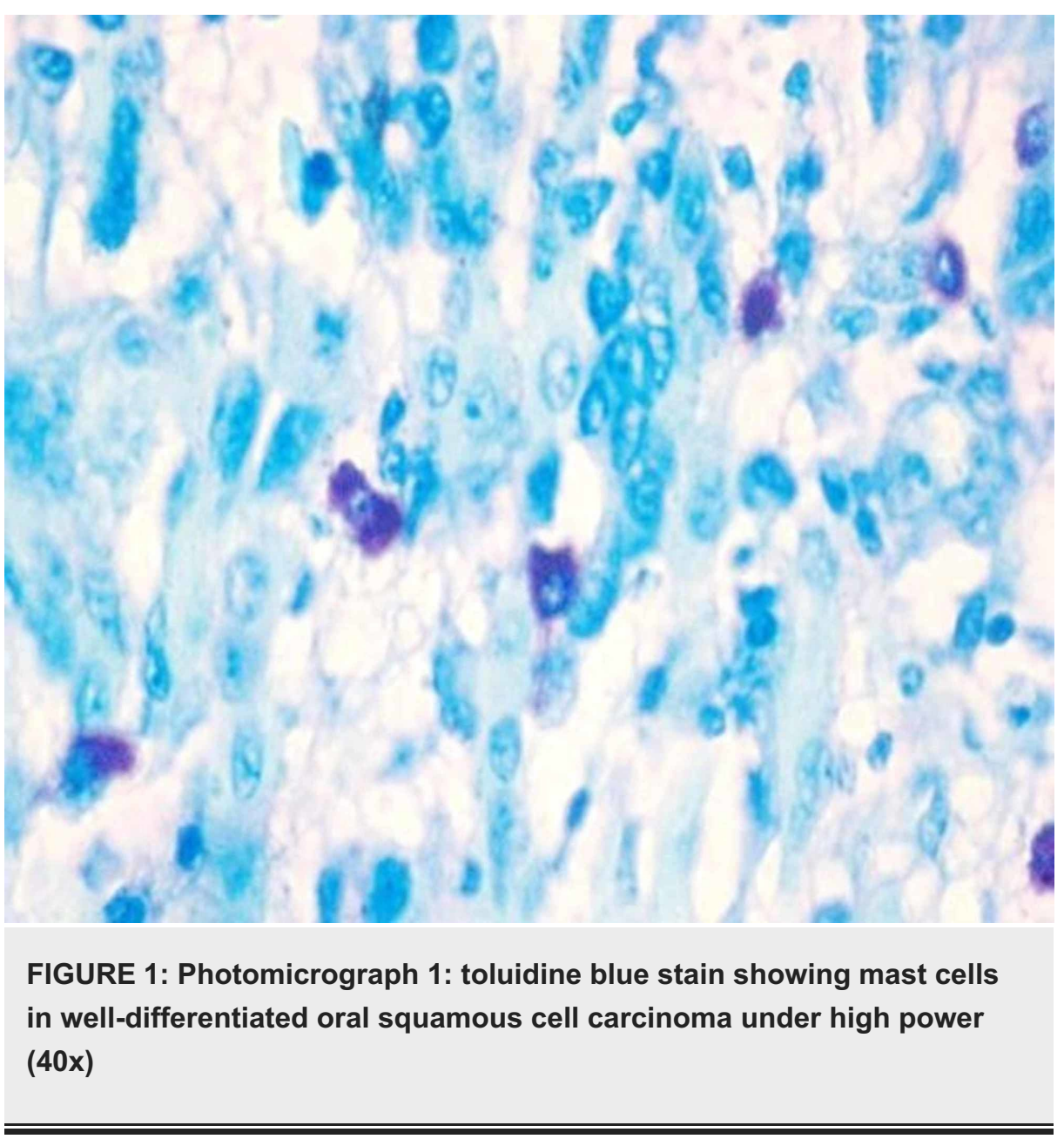




\section{Cureus}

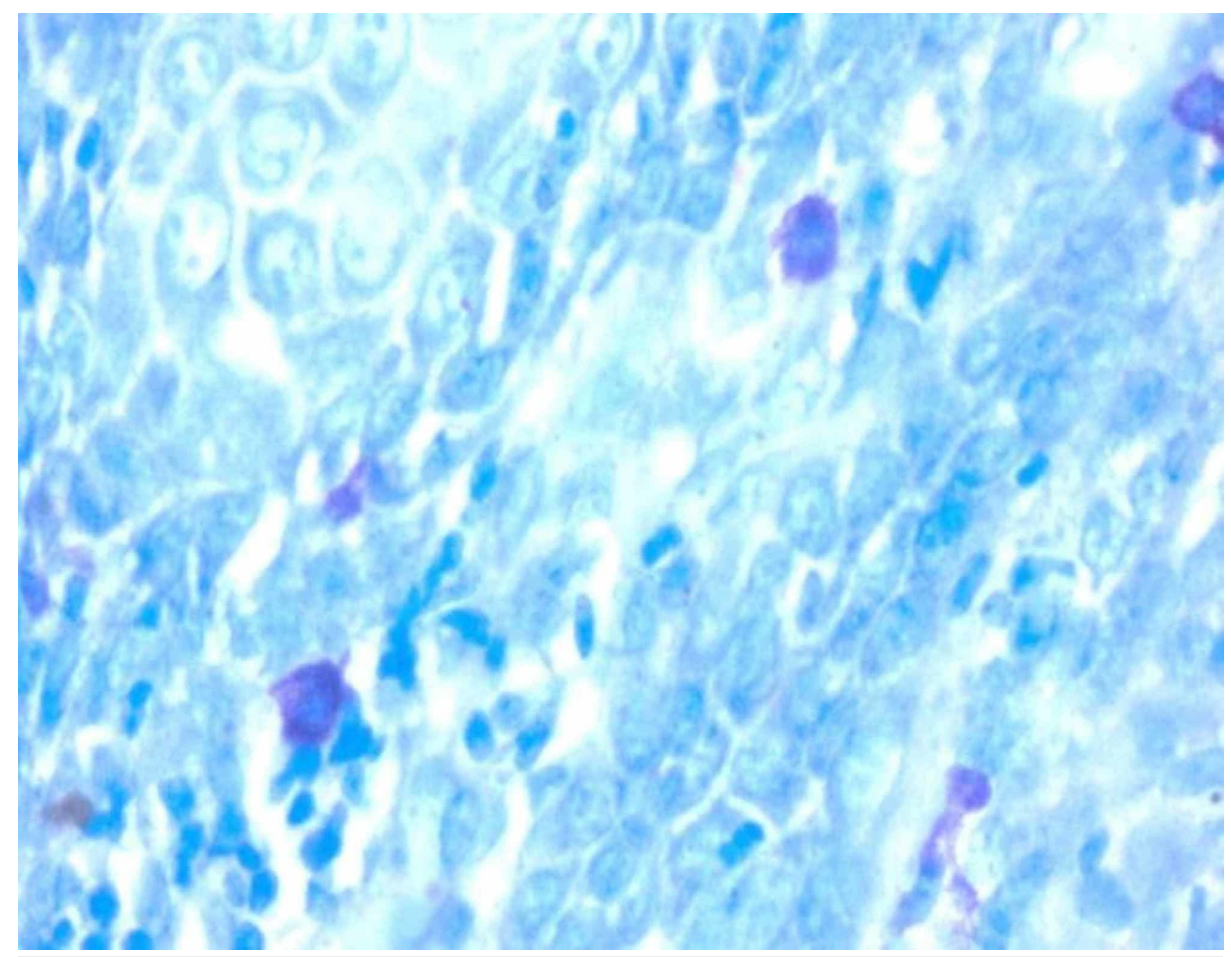

FIGURE 2: Photomicrograph 2: toluidine blue stain showing mast cells in moderately differentiated oral squamous cell carcinoma under high power (40x)

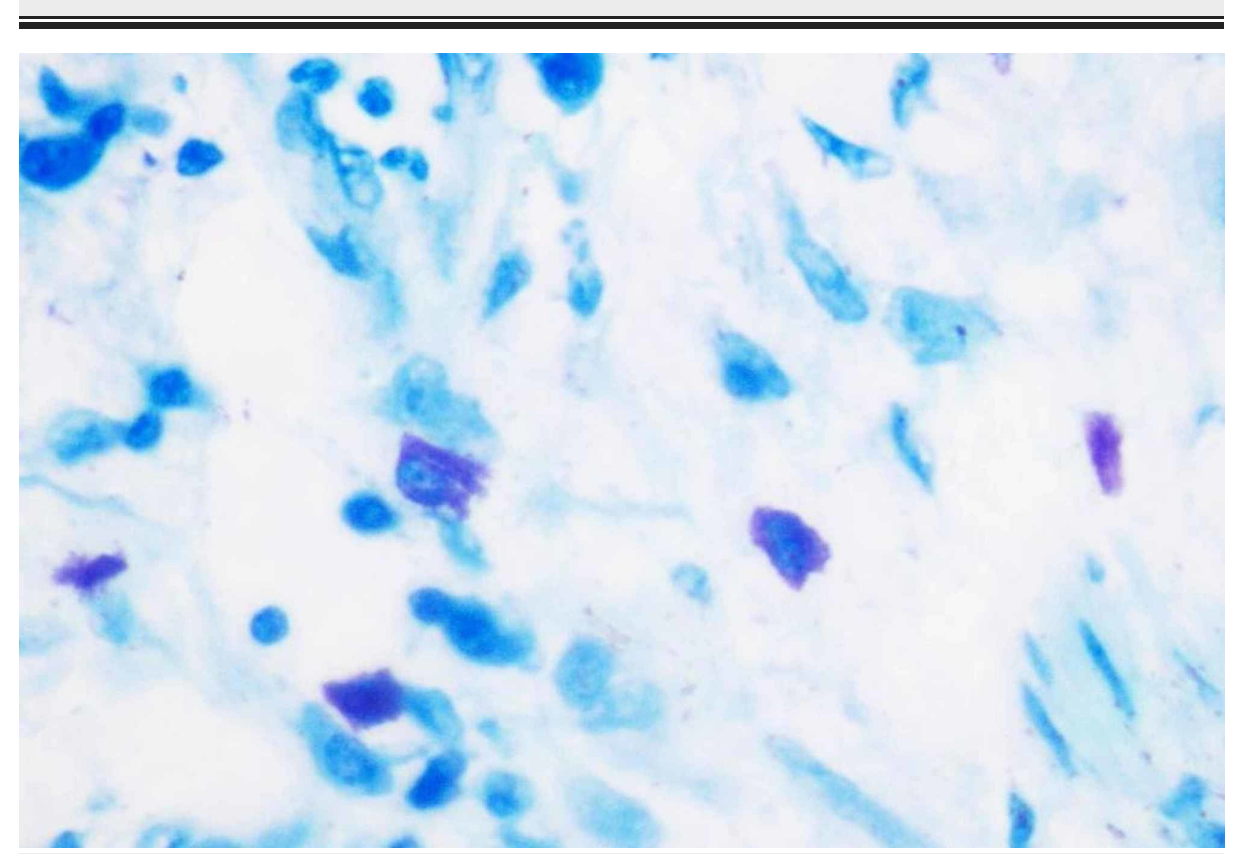

FIGURE 3: Photomicrograph 3: toluidine blue stain showing mast cells in poorly differentiated oral squamous cell carcinoma under high power (40x) 


\section{Cureus}

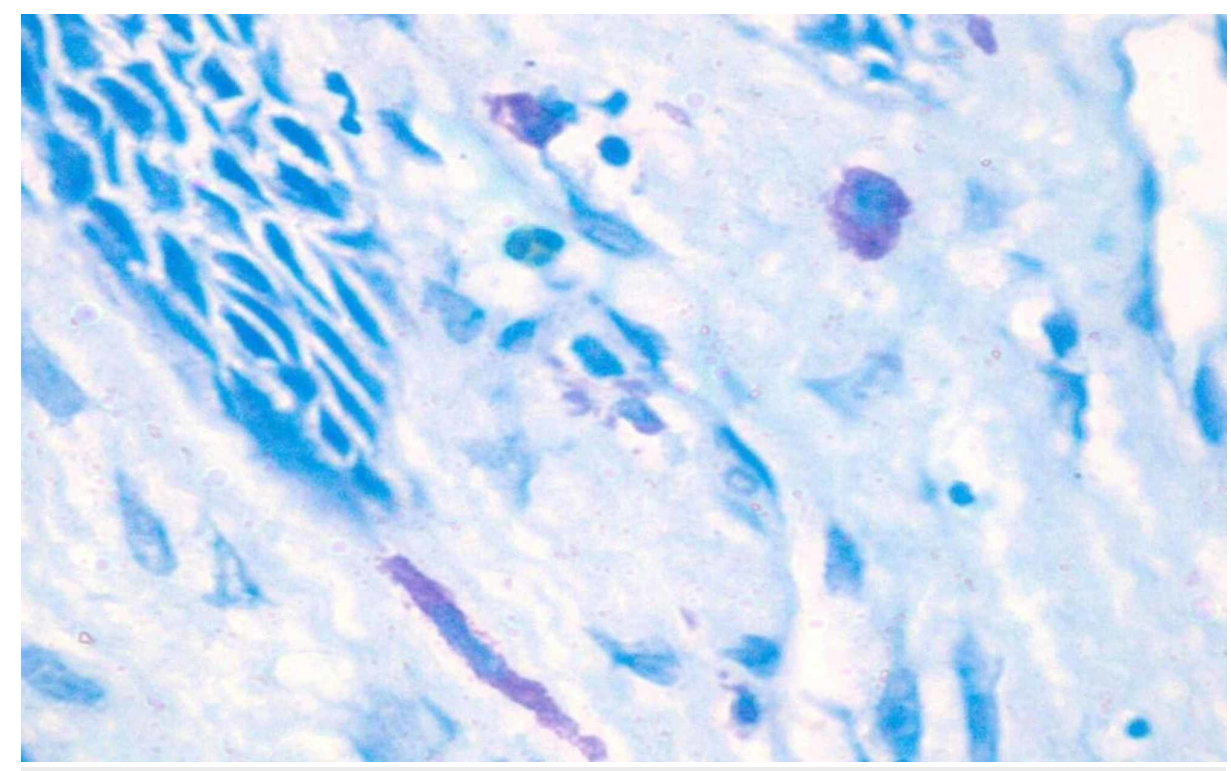

FIGURE 4: Photomicrograph 4: toluidine blue stain showing mast cells in normal oral mucosa under high power $(40 x)$

\section{Evaluation of mast cells and analysis}

Under the light microscope, MCs appearing as pinkish/purple-colored spindle to oval-shaped cells with sky blue-colored nuclei were evaluated. Counting was carried out in five random high-power fields (40x) having a larger number of MCs, with one field depth from the basement membrane of the epithelium and the average per high field (HF) were determined, further the MCC was expressed per square mm within the radius of one field under the high-power objective (40x). All the data were tabulated and a one-way analysis of variance (ANOVA) test was performed to compare and evaluate the number of MCCs in histologically diagnosed OSCC and normal mucosa. This was done to compare and evaluate the MCC in well-differentiated OSCC, moderately differentiated OSCC, and poorly differentiated OSCC using the Statistical Package for Social Sciences (SPSS), version 19.0 (IBM SPSS Statistics, Armonk, NY).

\section{Results}

The study comprised 60 samples including 15 cases of well-differentiated OSCC, 15 cases of moderately differentiated OSCC, 15 cases of poorly differentiated OSCC, and 15 cases of normal mucosa. One-way ANOVA performed to compare the mean MCC between the three grades of OSCC (well-differentiated, moderately differentiated, and poorly differentiated) and the control group (normal mucosa) showed a pvalue of 0.1311 . The $p$-value was not found to be significant at $\alpha=0.05(p<0.05)$, denoting there was no substantial difference in the mean MCC among the study groups (Table 1). The paired t-test was performed for comparisons within the groups which showed the mean MMC was comparatively more in normal mucosa than in various grades of OSCC, and it was higher in low-grade OSCC in comparison with well- and moderately differentiated OSCC (Table 2).

\begin{tabular}{|l|l|l|}
\hline STUDY GROUPS & Mean Mast Cell Count & p-value (One-way ANOVA) \\
\hline Normal mucosa (Control) & 7.7 & \\
Well-differentiated OSCC (WDSCC) & 7.1 & $0.131^{*}$ \\
Moderately differentiated OSCC (MDSCC) & 4.7 & \\
Poorly differentiated OSCC (PDSCC) & 4.5 & \\
\hline
\end{tabular}

\section{TABLE 1: The Mean Mast Cell Count and Observed P-Value by One-Way ANOVA}

${ }^{*} \mathrm{p}$-value is not significant $(\mathrm{P}<0.05$ significance level)

ANOVA: analysis of variance; OSCC: oral squamous cell carcinoma 


\section{Cureus}

\begin{tabular}{|c|c|c|}
\hline COMPARISON GROUPS & t-value & p-value \\
\hline Normal mucosa vs WDSCC & -0.081741 & 0.9355 \\
\hline Normal mucosa vs WDSCC & -1.6334 & 0.1136 \\
\hline Normal mucosa vs WDSCC & -1.6709 & 0.1067 \\
\hline PDSCC vs MDSCC & -0.12663 & 0.9002 \\
\hline PDSCC vs WDSCC & 1.8326 & 0.07752 \\
\hline MDSCC vs WDSCC & 1.7491 & 0.09165 \\
\hline
\end{tabular}

TABLE 2: The Mean Mast Cell Count and Observed P-Value Within the Groups by T-Test

MDOSCC: moderately differentiated oral squamous cell carcinoma; PDOSCC: poorly differentiated oral squamous cell carcinoma; WDOSCC: welldifferentiated oral squamous cell carcinoma

\section{Discussion}

Oral cancer is often diagnosed at the later stages of the disease where most individuals present with localized or regional involvement of the tumor cells (37\% localized, $43 \%$ regional site, $10 \%$ distant or specific) [8]. In India, OSCC is one of the leading causes of increased mortality rates in head and neck malignancies. Studies have shown prognosis and five-year survival rates range from $79 \%$ for those with localized disease, $42 \%$ for regional disease, and $19 \%$ for distant metastasis cases $[7,9]$. Progression of oral cancer proceeds through distinct molecular genetic alterations and mutations that are acquired from the loss of genomic integrity following exposure to associated risk factors over a prolonged period of time [6-7]. Neovascularization or angiogenesis is an essential component in a number of regular physiologic processes, including growth and development, healing of oral wounds, and reproduction. It is also considered a critical step in the growth and progression of tumor cells. MCs are effector cells of inflammatory and allergic response/stimuli originated from multilineage hematopoietic progenitors that migrate to tissues and organs where they eventually mature and reside [10-12]. MCs are a well-recognized source of various proinflammatory mediators and express the high-affinity IgE receptor on their cell surface.

Various studies have shown MCs regulate carcinogenesis by immunosuppression, angiogenesis enhancement, and promotion of tumor cell mitosis. Increased accumulation of MCs within tumor environments has been correlated with poor prognosis, increased metastasis, and reduced survival in melanoma, adenocarcinomas, squamous cell carcinoma, Hodgkin lymphoma, and B-cell leukemias [13-14]. Our study results were similar to results obtained in the study done by Dastpak et al. and Cheema et al. where MCs were decreased in OSCC in comparison with the normal oral mucosa, suggesting that MCs do not play an important role in tumor progression $[6,15]$. In the present study, the mean MCC between the groups was insignificant, similar to results obtained in the study done by Dastpak et al. where the average amount of MCs decreased in OSCC in comparison with normal oral mucosa [6]. The result of this study is similar to the study by Oliveira-Neto et al. where they found that the MC density was lower in OSCC and in premalignant lesions in comparison with the control group [16]. This could be attributed to the migration failure of the MCs, which possibly is reflected as an adaptation variation in the microenvironment during the tumor initiation and progression. From the present study, it can be observed that mast cells are the key immune cells present in the tumor microenvironment. The receptors present on the surface upon stimulation may release proangiogenesis factors, such as vascular endothelial growth factor (VEGF), basic fibroblastic growth factor (bFGF), transforming growth factors, IL-8, matrix metalloproteinase, tryptase, and chymase that participate in the neoangiogenesis or vascular formation process. Kalra et al., Michailidou et al., and Tahir et al. observed that the MCC in high-grade OSCC was significantly higher than normal oral mucosa, so these studies are in contrast with the present study [7, 17-18]. This difference may be due to the difference between the location of tumors and the demographic parameters of our study, such as the patient's age and sex.

\section{Conclusions}

In the present study, the highest MCC was seen in normal tissue and it was higher in low-grade OSCC in comparison with high-grade. However, the differences between groups were not statistically significant. The same result was seen between high-grade and low-grade OSCC. Therefore, we conclude that the mean MCC was decreased in OSCC in comparison with normal oral mucosa. Hence, it can be assumed that MCs could serve as a possible indicator of tumor progression. However, further studies on the evaluation of various mediators are prerequisites to draw a conclusion on the exact role of MCs in tumor progression.

\section{Additional Information}




\section{Disclosures}

Human subjects: Consent was obtained by all participants in this study. Institutional Review Board of Rajarajeswari Dental College and Hospital issued approval NA. The study is permitted to be carried out in the laboratory environment by sectioning the paraffin-embedded oral squamous cell carcinoma tissue blocks. Animal subjects: All authors have confirmed that this study did not involve animal subjects or tissue. Conflicts of interest: In compliance with the ICMJE uniform disclosure form, all authors declare the following: Payment/services info: All authors have declared that no financial support was received from any organization for the submitted work. Financial relationships: All authors have declared that they have no financial relationships at present or within the previous three years with any organizations that might have an interest in the submitted work. Other relationships: All authors have declared that there are no other relationships or activities that could appear to have influenced the submitted work.

\section{References}

1. Bunget AM, Dascălu IT, Coleș E, Țîrcă T, Stan M, Găman Su, Nicola AG: Histopathological aspects in oral squamous cell carcinoma. J Dental Sci. 2018, 3:000173.

2. Soderberg ML: The mast cell activation syndrome. A mini review . MOL Immunol. 2015, 2:00032. 10.15406/moji.2015.02.00032

3. Sridharan G, Shankar AA: Toluidine blue: a review of its chemistry and clinical utility . J Oral Maxillofac Pathol. 2012, 16:251-255. 10.4103/0973-029X.99081

4. Kheur S, Patekar D, Bagul N, Kulkarni M, Routray S, Dhas V: Role of mast cell in oral pathology . Oral Max Path J. 2013, 4:320-325.

5. Ribatti D: The staining of mast cells: a historical overview . Int Arch Allergy Immunol. 2018, 176:55-60. 10.1159/000487538

6. Dastpak M, Nafarzadeh S, Khafri S: A comparative study on the mast cells count in oral squamous cell carcinoma and normal oral mucosa. Caspian J Dent Res. 2015, 4:17-22. 10.22088/cjdr.4.1.17

7. Kalra M, Rao N, Nanda K, Rehman F, Girish KL, Tippu S, Arora A: The role of mast cells on angiogenesis in oral squamous cell carcinoma. Med Oral Patol Oral Cir Bucal. 2012, 17:e190-e196. 10.4317/medoral.17395

8. Boring CC, Squires TS, Tong T, Montgomery S: Cancer statistics, 1994. CA Cancer J Clin. 1994, 44:7-26. 10.3322/canjclin.44.1.7

9. Field JK: Oncogenes and tumor suppressor genes in squamous cell carcinoma of head and neck . Eur J Cancer B Oral Oncol. 1992, 28B:67-76. 10.1016/0964-1955(92)90016-t

10. Gaddikeri K, Bhorgonde DD : Assessment of role of mast cells in oral squamous cell carcinoma; . Asian Pac J Health Sci. 2016, 3:63-66. 10.21276/APJHS.2016.3.4S.9

11. Durairaj G, Venkatapathy R, Prasad KV, Premalatha B: Comparative analysis of mast cell density in various grades of oral squamous cell carcinoma - a trial study. Indian J Appl Res. 2017, 7:170-173.

12. Makkar I, Metgud R, Vyas Z, Tak A: Markers of angiogensis in potentially malignant lesions and oral squamous cell carcinoma. J Adv Med Dent Scie Res. 2016, 4:25-34.

13. Spoorthi BR, Gurram Shankar Vidya GS: mast cell count analysis in oral Inflammatory lesions, potentially malignant disorder and oral squamous cell carcinoma. Int J Sci Res Public. 2013, 3:1-4.

14. Maciel TT, Moura IC, Hermine O: The role of mast cells in cancers . F1000Prime Rep. 2015, 7:09. 10.12703/P7-09

15. Cheema VS, Ramesh V, Balamurali PD: The relevance of mast cells in oral squamous cell carcinoma . J Clin Diagn Res. 2012, 6:1803-1807. 10.7860/JCDR/2012/4503.2616

16. Oliveira-Neto HH, Leite AF, Costa NL, et al.: Decrease in mast cells in oral squamous cell carcinoma: possible failure in the migration of these cells. Oral Oncol. 2007, 43:484-490. 10.1016/j.oraloncology.2006.05.004

17. Michailidou EZ, Markopoulos AK, Antoniades DZ: Mast cells and angiogenesis in oral malignant and premalignant lesions. Open Dent J. 2008, 2:126-132. 10.2174/1874210600802010126

18. Tahir A, Nagi AH, Ullah E, Janjua OS: The role of mast cells and angiogenesis in well- differentiated oral squamous cell carcinoma. J Cancer Res Ther. 2013, 9:387-391. 10.4103/0973-1482.119311 